\title{
Water Vapor Adsorption Capacity of Thermally Fluorinated Carbon Molecular Sieves for $\mathrm{CO}_{2}$ Capture
}

\author{
Jin-Young Jung, ${ }^{1}$ Hye-Ryeon Yu, ${ }^{1}$ Se Jin In, ${ }^{2}$ Young Chul Choi, ${ }^{3}$ and Young-Seak Lee ${ }^{1}$ \\ ${ }^{1}$ Department of Applied Chemistry and Biological Engineering, Chungnam National University, Daejeon 305-764, Republic of Korea \\ ${ }^{2}$ Department of Fire and Disaster Protection Engineering, Woosong University, Daejeon 300-718, Republic of Korea \\ ${ }^{3}$ CNT Team, Hanwha Chemical Corporation, Incheon 403-030, Republic of Korea
}

Correspondence should be addressed to Young Chul Choi; youngchoi@hanwha.com and Young-Seak Lee; youngslee@cnu.ac.kr

Received 13 August 2013; Accepted 23 August 2013

Academic Editor: Yun Suk Huh

Copyright (C) 2013 Jin-Young Jung et al. This is an open access article distributed under the Creative Commons Attribution License, which permits unrestricted use, distribution, and reproduction in any medium, provided the original work is properly cited.

\begin{abstract}
The surfaces of carbon molecular sieves (CMSs) were thermally fluorinated to adsorb water vapor. The fluorination of the CMSs was performed at various temperatures $\left(100,200,300\right.$, and $\left.400^{\circ} \mathrm{C}\right)$ to investigate the effects of the fluorine gas $\left(\mathrm{F}_{2}\right)$ content on the surface properties. Fluorine-related functional groups formed were effectively generated on the surface of the CMSs via thermal fluorination process, and the total pore volume and specific surface area of the pores in the CMSs increased during the thermal fluorination process, especially those with diameters $\leq 8 \AA$. The water vapor adsorption capacity of the thermally fluorinated CMSs increased compared with the as-received CMSs, which is attributable to the increased specific surface area and to the semicovalent bonds of the C-F groups.
\end{abstract}

\section{Introduction}

Carbon dioxide $\left(\mathrm{CO}_{2}\right)$ emission which is responsible for more than $60 \%$ of global warming has received worldwide concern. One-third of global $\mathrm{CO}_{2}$ emissions result from human activities, especially from fossil fuel electric power plants [1]. Many technologies are being developed to reduce the $\mathrm{CO}_{2}$ emissions from the resulting flue gas of power generation. Carbon capture and storage (CCS) has recently been the subject of significant research and has been regarded as a promising way to mitigate and control $\mathrm{CO}_{2}$ emissions [2]. Generally, polymeric adsorbents, zeolites, silica gels, activated carbons, and molecular sieves have been extensively used as selective adsorbents because of their controllable pore structures and surface properties, which can be used to selectively capture $\mathrm{CO}_{2}[3,4]$. Among these adsorbents, molecular sieves have the ability to selectively absorb specific components of gaseous mixtures because of their porous structures, which consist of relatively uniform pores that are several angstroms $(\AA)$ or nanometers $(\mathrm{nm})$ in diameter. Carbon molecular sieves (CMSs) possess narrow and specific pore size distributions (PSDs) contrary to other conventional absorbents. "The unique pore size distribution imparts CMSs with remarkable selectivity in molecular separations." [5]. In addition, CMSs are more shape-selective for planar molecules than other molecular sieves and are stable at high temperatures [6].

The elimination of water vapor with $\mathrm{CO}_{2}$ has recently received considerable amounts of attention because of promising application in air reparation, gas separation, environmental protection, and purification [7-9]. Accurate models for characterizing water adsorption are required to enhance water removal processes. Numerous studies are being conducted to investigate the water vapor adsorption process which has various advantages, such as low operating costs and high selectivity on adsorbents [10-12]. Moreover, used adsorbents are easy to regenerate and possess high adsorption capacities and separation rates [3]. The adsorption kinetics of molecules is dependent on the size, shape, and electrical properties of the adsorbate. These adsorbate properties induce specific interactions with the adsorbent $[13,14]$.

Various treatments, such as oxidation, amination, and fluorination, can be used to modify carbon surfaces to improve the adsorption of $\mathrm{CO}_{2}$ and water vapor [15-20]. 
Of these surface treatments, the direct fluorination method under a gas phase reaction has received a substantial attention because of its potential for uniform modification, short reaction time, low cost, and efficiency [21]. Fluorination causes defects, changes surface properties, and increases the total number of basic sites with varying degrees of basicity on carbon materials [22-25]. Furthermore, the nature of surface carbons can be adjusted by direct fluorination, regardless of whether they are hydrophilic or hydrophobic [26].

In this work, the surfaces of CMSs were modified by thermal fluorination, which can be conducted via a simple procedure under a gas phase reaction. Thermal fluorination altered the surface properties and pore structures of the CMSs and exhibited significant effects on the water vapor adsorption capacity. A mechanism is also proposed for the improved water vapor adsorption capacity of CMSs after the thermal fluorination treatment.

\section{Experimental}

2.1. Preparation of Thermal Fluorinated CMSs. The surfaces of CMSs (CMS FB610, CarboTech AC GmbH, Germany) were treated using a fluorination apparatus consisting of a SUS304 reactor, a vacuum pump, a nickel boat, and a buffer tank connected to gas cylinders. The samples were loaded into the reactor in a nickel boat and were degassed at $100^{\circ} \mathrm{C}$ for $2 \mathrm{~h}$ to remove moisture. Fluorine gas $\left(\mathrm{F}_{2} ; 99.8 \%\right.$, Messer Grieheim $\mathrm{GmbH})$ and nitrogen gas $\left(\mathrm{N}_{2} ; 99.999 \%\right)$ were used during the fluorination process. Fluorination was performed at $0.1 \mathrm{MPa}$ for $30 \mathrm{~min}$ using a $\mathrm{F}_{2}: \mathrm{N}_{2}$ gas volume ratio of $1: 9$. The thermal fluorination treatment was performed at 100, 200,300 , and $400^{\circ} \mathrm{C}$. After fluorination, the treated samples were degassed to remove the unreacted gases. Additional details regarding the fluorination procedure can be found in earlier works [27-29]. The as-received and treated CMSs were labeled PC (pristine CMSs), 100FC, 200FC, 300FC, and $400 \mathrm{FC}$ according to the temperature conditions.

2.2. Characterization of the Samples. X-ray photoelectron spectra (XPS) were obtained using a MultiLab 2000 spectrometer (Thermo Electron Corporation, UK) to identify the elements present in the samples. Aluminum $\mathrm{K} \alpha(1485.6 \mathrm{eV})$ radiation was used as the $\mathrm{X}$-ray source, and an anode voltage of $14.9 \mathrm{keV}$, a filament current of $4.6 \mathrm{~A}$, and an emission current of a $20 \mathrm{~mA}$ were applied. All samples were treated at $10^{-12} \mathrm{MPa}$ to remove impurities. Survey spectra were obtained at a pass energy of $50 \mathrm{eV}$ in increments of $0.5 \mathrm{eV}$. The pore characteristics of the samples were evaluated by determining the physical adsorption of $\mathrm{CO}_{2}$ in an ASAP 2020 (Micromeritics Ins. Corp.) at $0^{\circ} \mathrm{C}$. The pore characteristics of the CMSs were investigated using $\mathrm{CO}_{2}(3.3 \AA)$ gas, because the CMSs have extremely small pore sizes (the diameter of $\mathrm{N}_{2}$ is $3.8 \AA$ ). The pore size distributions (PSDs) of the CMSs were calculated using density functional theory (DFT) with the DFT Plus software supplied by Micromeritics [30, 31].

2.3. Water Vapor Adsorption/Desorption of the Prepared CMSs. To investigate the water vapor adsorption characteristics of the CMSs, dynamic vapor sorption (DVS) analyses
TABLE 1: XPS parameters of fluorinated CMS and PC.

\begin{tabular}{|c|c|c|c|c|}
\hline \multirow{2}{*}{ Sample } & \multicolumn{3}{|c|}{ Elemental content (at.\%) } & \multirow{2}{*}{$\mathrm{F} / \mathrm{C}(\%)$} \\
\hline & Cls & O1s & F1s & \\
\hline PC & 90.69 & 9.31 & - & - \\
\hline $100 \mathrm{FC}$ & 67.68 & 8.16 & 24.16 & 0.36 \\
\hline $200 \mathrm{FC}$ & 65.73 & 8.71 & 25.56 & 0.39 \\
\hline $300 \mathrm{FC}$ & 63.99 & 7.74 & 28.27 & 0.44 \\
\hline $400 \mathrm{FC}$ & 72.38 & 7.36 & 20.26 & 0.28 \\
\hline
\end{tabular}

at.\% means atomic percent of each atom.

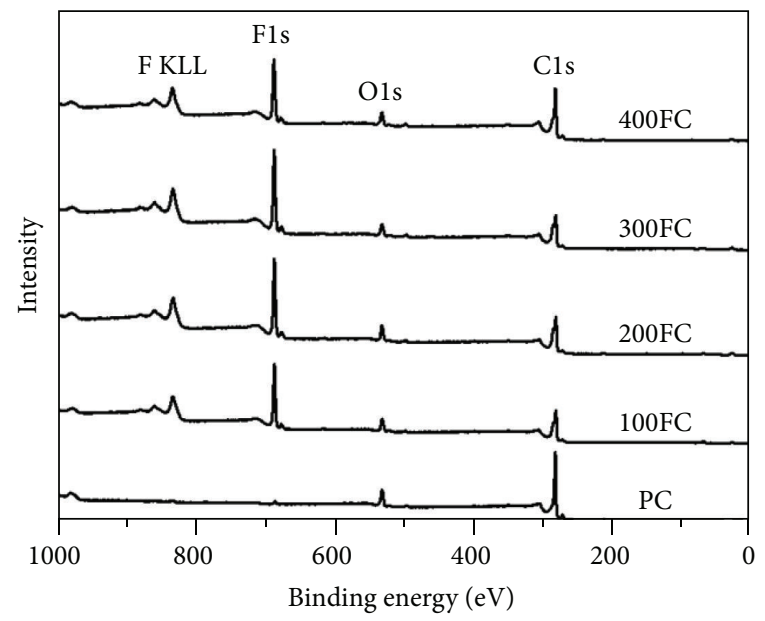

Figure 1: XPS survey spectra of PC, 100FC, 200FC, 300FC, and 400FC.

were conducted using a compact and economical DVS system (DVS Int.). The prepared CMSs were dried at $150^{\circ} \mathrm{C}$ for $1 \mathrm{~h}$ to remove moisture. The DVS analysis was performed at $25^{\circ} \mathrm{C}$ for $1200 \mathrm{~min}$. The relative humidity ranged from 0 to $98 \%$.

\section{Results}

3.1. Effects of Thermal Fluorination on the Chemical Composition of CMSs. The functional groups introduced onto the surfaces of the CMSs were identified after examining the C1s and F1s XPS peaks after thermal fluorination, and the results are provided in Table 1 and Figure 1. As shown in Figure 1, the XPS survey graphs of pristine CMSs and thermally fluorinated CMSs displayed a distinct carbon peak at $284.5 \mathrm{eV}$. Fluorine and oxygen peaks were also observed at 687.7 and $531.0 \mathrm{eV}$, respectively, in the spectra of the fluorinated CMSs. The atomic ratio of each element on the surface of the CMSs is listed in Table 1. The carbon content of the samples decreased remarkably by approximately $28 \%$, and an increase in the fluorine content was observed after thermal fluorination. However, the fluorine content of 400FC was lower than that of $100 \mathrm{FC}, 200 \mathrm{FC}$, and $300 \mathrm{FC}$. This phenomenon is attributed to the effects of defluorination at high temperature. The loss of fluorine was initiated between 200 and $300^{\circ} \mathrm{C}$, and defluorination was mostly completed by $400^{\circ} \mathrm{C}[32,33]$. Based on these results, the fluorine contents 
TABLE 2: Assignments and peak parameters of the different Cls components.

\begin{tabular}{|c|c|c|c|c|c|c|c|}
\hline \multirow{2}{*}{ Component } & \multirow{2}{*}{ Assignment } & \multirow{2}{*}{ Binding energy $(\mathrm{eV})$} & \multicolumn{5}{|c|}{ Concentration (\%) of each sample } \\
\hline & & & PC & $100 \mathrm{FC}$ & 200FC & $300 \mathrm{FC}$ & $400 \mathrm{FC}$ \\
\hline $\mathrm{C}(1)$ & $\mathrm{C}-\mathrm{C}\left(\mathrm{sp}^{2}\right)$ & 284.5 & 70.24 & 36.48 & 34.79 & 35.36 & 52.91 \\
\hline$C(2)$ & $C-C\left(\mathrm{sp}^{3}\right)$ & 285.4 & 18.13 & 18.82 & 19.29 & 20.23 & 18.95 \\
\hline $\mathrm{C}(3)$ & $\mathrm{C}-\mathrm{O}$ & 286.4 & 7.49 & 12.48 & 13.73 & 13.30 & 10.12 \\
\hline $\mathrm{C}(4)$ & $\mathrm{C}=\mathrm{O}$ & 287.4 & 4.14 & 12.31 & 11.82 & 10.01 & 6.48 \\
\hline$C(5)$ & Semicovalent C-F & 288.8 & 0 & 15.56 & 15.79 & 16.07 & 9.20 \\
\hline$C(6)$ & $\mathrm{C}-\mathrm{F}$ & 290.5 & 0 & 4.35 & 4.91 & 5.03 & 2.34 \\
\hline
\end{tabular}

of $200 \mathrm{FC}$ and $300 \mathrm{FC}$ gradually increased to $25.56 \%$ and $28.27 \%$, respectively. However, the fluorine contents of $400 \mathrm{FC}$ decreased to $20.26 \%$, which is less than that of the contents of $100 \mathrm{FC}$ due to the occurrence of defluorination at high temperatures.

To investigate the changes in the functional groups on the surfaces of the thermally fluorinated CMSs, the Cls peaks were deconvoluted to several pseudo-Voigt functions (sums of the Gaussian-Lorentzian function) using a peak analysis program obtained from Unipress Co., USA. The pseudo-Voigt function is given by [34]

$$
\begin{gathered}
F(E)=H\left[(1-S) \exp \left(-\ln (2)\left(\frac{E-E_{0}}{\mathrm{FWHM}}\right)^{2}\right)\right. \\
\left.+\frac{S}{1+\left(\left(E-E_{0}\right) / \mathrm{FWHM}\right)^{2}}\right],
\end{gathered}
$$

where $F(E)$ is the peak intensity at energy $E, H$ is the peak height, $E_{0}$ is the peak center, FWHM is the full width at half-maximum, and $S$ is the shape function, which is related to the symmetry and to the Gaussian-Lorentzian mixing ratio. The assignments and peak parameters of the different $\mathrm{C} 1$ s components are provided in Table 2 . The semicovalent $(\mathrm{C}(5))$ bonds of the thermally fluorinated CMSs increased compared to pristine CMSs. A detailed explanation is presented in Section 4 using the water vapor adsorption capacity results. In addition, values of $\mathrm{C}-\mathrm{C}$; $\mathrm{sp}^{2}(\mathrm{C}(1))$ bonds in 400FC were higher than those in 100FC, 200FC, and $300 \mathrm{FC}$, because fluorine can be removed by high-temperature fluorination and the $\pi$-electron systems can be significantly recovered through heat treatment [35-37].

\subsection{Effect of Thermal Fluorination on the Pore Character-} istics of CMSs. The pore characteristics of the thermally fluorinated CMSs were investigated, and the results are shown in Table 3 . The total pore volumes of the thermally fluorinated CMSs increased due to fluorination via heat treatment, whereas the total pore volume of 400FC slightly decreased. As mentioned in Section 3.1, this result occurred due to defluorination at high temperatures. In addition, the area in the CMSs pores $>10.83 \AA$ decreased after thermal fluorination, which was accompanied by an increase in the total volume. Therefore, the destruction of pores via thermal fluorination is responsible for the increase in the pore area.
TABLE 3: Changes in the pore characteristics of the treated CMSs according to fluorination temperature.

\begin{tabular}{lccccc}
\hline Sample & PC & 100FC & 200FC & 300FC & $400 \mathrm{FC}$ \\
\hline $\begin{array}{l}\text { Total pore volume } \\
\left(\mathrm{cm}^{3} / \mathrm{g}\right)\end{array}$ & 0.1008 & 0.1016 & 0.1083 & 0.1143 & 0.1117 \\
$\begin{array}{l}\text { Specific surface area } \\
\left(\mathrm{m}^{2} / \mathrm{g}\right)\end{array}$ & 433.66 & 459.95 & 455.89 & 439.46 & 438.55 \\
\hline
\end{tabular}

Figures 2 and 3 present the PSDs of the CMSs calculated using DFT. The pore volumes of $\angle 5 \AA$ of $100 \mathrm{FC}$ and $200 \mathrm{FC}$ were greater than those of the CMSs. The pore volumes of $>10 \AA$ of $300 \mathrm{FC}$ and $400 \mathrm{FC}$ were also greater than those of the CMSs. The pore volumes of $<6 \AA$ of $400 F C$ were recovered. As shown in Figure 3, the volumes of the pores in the thermally fluorinated CMSs (especially those with diameters $<8 \AA$ ) were greater than those of the untreated CMSs.

\subsection{Water Vapor Adsorption Behavior of Prepared Samples.} Figure 4 presents the water vapor adsorption capacities of the prepared samples. The adsorption capacities increased considerably following fluorination with heat treatment, and the following trend in mass change was observed: $\mathrm{PC}<$ 300FC, 400FC < 200FC < 100FC. These following trends were caused by the semicovalent $(\mathrm{C}(5))$ bonds contents and the total carbon adsorbents areas. In the $\mathrm{C}-\mathrm{F}$ bonds of $\mathrm{F}$ species, the ionic and semi-covalent $\mathrm{C}-\mathrm{F}$ bond lengths (3.0 and $1.7 \AA$ ) were both larger than the usual covalent $\mathrm{C}-\mathrm{F}$ bond length (1.41 $\AA$ ). The larger dipoles of the ionic or semicovalent $\mathrm{C}-\mathrm{F}$ bond provide greater polarity than that of the covalent $\mathrm{C}-\mathrm{F}$ bond [38]. Bismarck et al. reported that the surface polarity of fluorinated carbon materials decreases C$\mathrm{F}$ bonding varying from ionic to semi-ionic to covalent [39]. Therefore, thermally fluorinated CMSs with comparatively large semi-covalent $\mathrm{C}-\mathrm{F}$ group were expected to exhibit improved water adsorption capacities. In addition, more water vapor can be adsorbed as the micropore volumes of the carbon adsorbents increase [40]. In the present study, the total pore volume and area increased due to the thermal fluorination. The water vapor adsorption capacity was altered according to the change in the total pore area. Therefore, the specific surface area of the CMSs has a more prominent effect on their water vapor adsorption capacity compared to introducing the fluorine functional groups on their surfaces through thermal fluorination. 


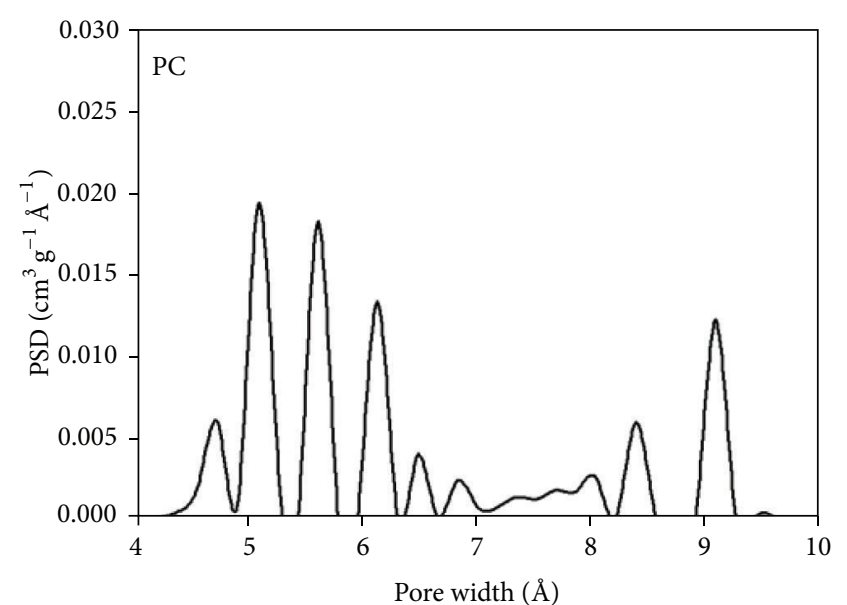

(a)

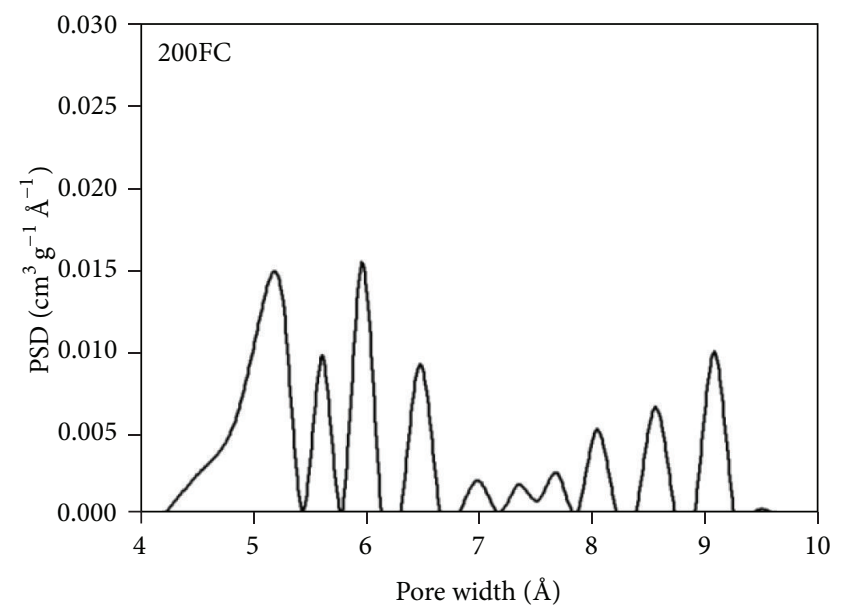

(c)

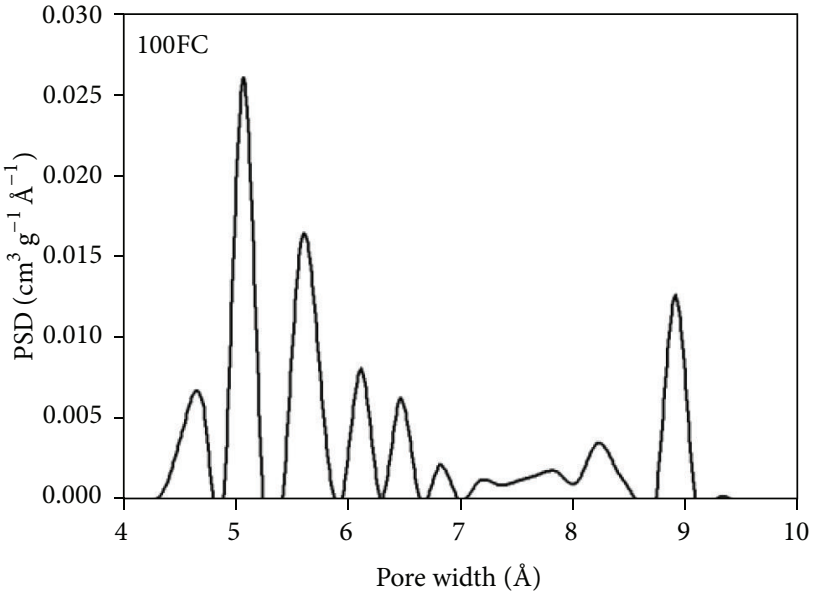

(b)

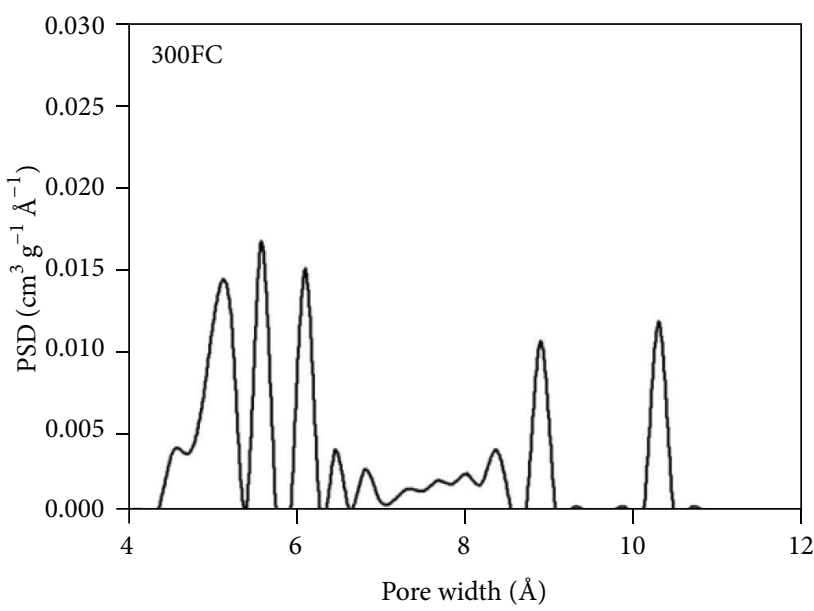

(d)

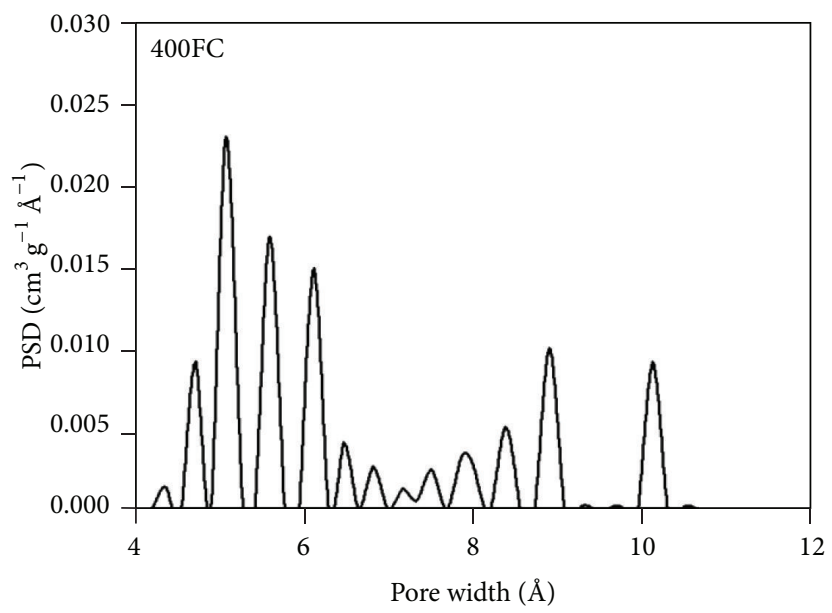

(e)

FIGURE 2: PSDs showing the development of CMSs porosity according to fluorination temperature.

\section{Conclusion}

Surface-modified CMSs were prepared via thermal fluorination at various temperatures $\left(100,200,300\right.$, and $\left.400^{\circ} \mathrm{C}\right)$ to investigate their water vapor adsorption properties. The improved water vapor adsorption capacity of the thermally fluorinated CMSs was due to the effects of the fluorination process on the specific surface area and semi-covalent bonds 


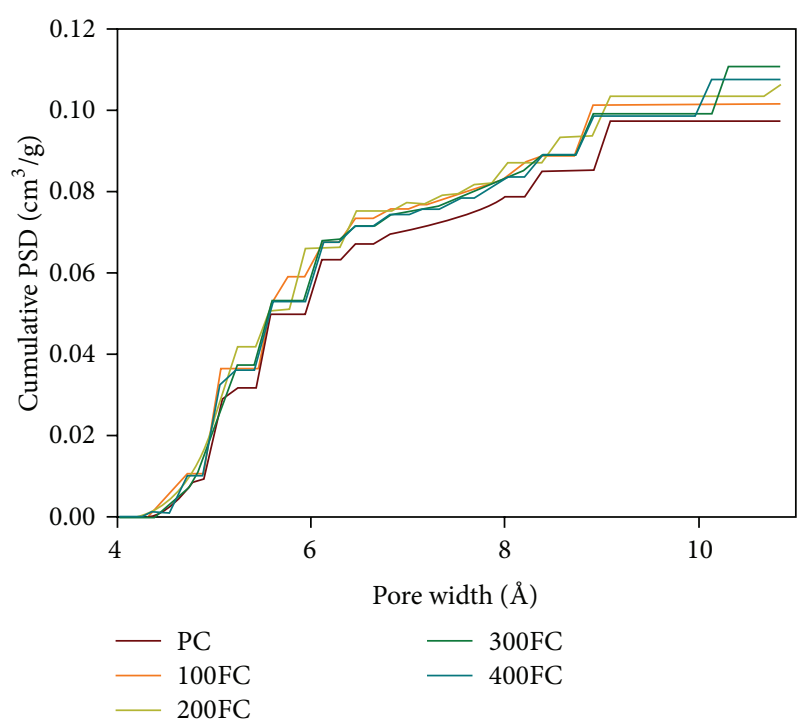

Figure 3: Cumulative PSDs of PC, 100FC, 200FC, 300FC, and 400FC.

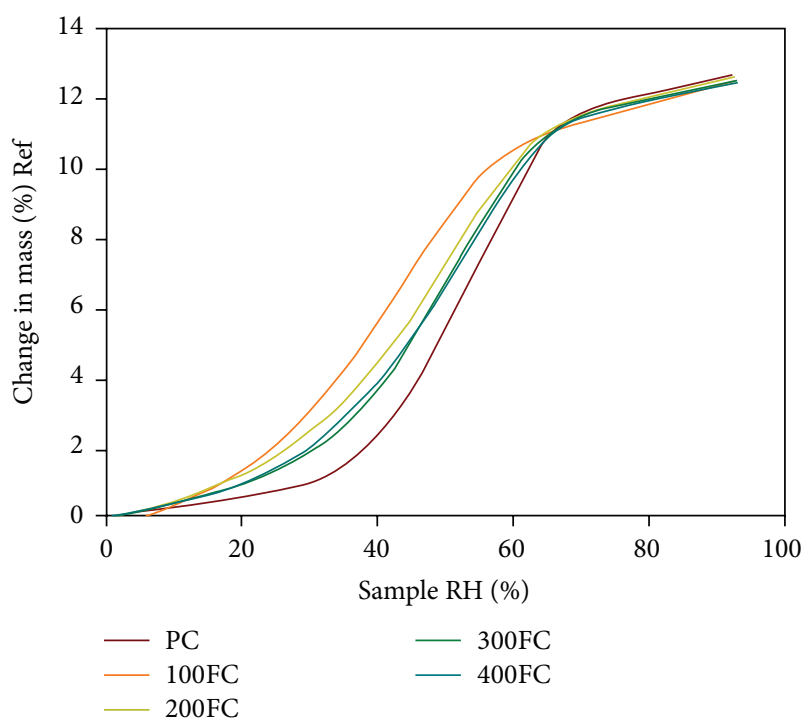

FIGURE 4: Water vapor adsorption isotherms of PC, 100FC, 200FC, $300 \mathrm{FC}$, and 400FC.

on the CMS surfaces. The specific surface areas of the CMSs have a more prominent effect on their water vapor adsorption capacity when compared to introducing fluorine functional groups on their surfaces through thermal fluorination.

\section{References}

[1] P. Freund and W. G. Ormerod, "Progress toward storage of carbon dioxide," Energy Conversion and Management, vol. 38, no. 1, pp. S199-S204, 1997.

[2] G. Li, P. Xiao, P. A. Webley, J. Zhang, and R. Singh, "Competition of $\mathrm{CO}_{2} / \mathrm{H}_{2} \mathrm{O}$ in adsorption based $\mathrm{CO}_{2}$ capture," Energy Procedia, vol. 1, no. 1, pp. 1123-1130, 2009.
[3] S. Sjostrom and H. Krutka, "Evaluation of solid sorbents as a retrofit technology for $\mathrm{CO}_{2}$ capture," Fuel, vol. 89, no. 6, pp. 1298-1306, 2010.

[4] S. Sircar, T. C. Golden, and M. B. Rao, "Activated carbon for gas separation and storage," Carbon, vol. 34, no. 1, pp. 1-12, 1996.

[5] J. P. Łukaszewicz and K. Zieliński, "Durability and narrow pore size distribution (PSD) of carbons fabricated from Salix viminalis wood," Chemical and Process Engineering, vol. 32, no. 3, pp. 195-201, 2011.

[6] P. L. Walker, L. G. Austin, and S. P. Nandi, Chemistry and Physics of Carbon, Marcel Dekker, New York, NY, USA, 1966.

[7] C. Nédez, J.-P. Boitiaux, C. J. Cameron, and B. Didillon, "Optimization of the textural characteristics of an alumina to capture contaminants in natural gas," Langmuir, vol. 12, no. 16, pp. 3927-3931, 1996.

[8] Y. Wang and M. D. LeVan, "Adsorption equilibrium of carbon dioxide and water vapor on zeolites $5 \mathrm{a}$ and $13 \mathrm{X}$ and silica gel: pure components," Journal of Chemical and Engineering Data, vol. 54, no. 10, pp. 2839-2844, 2009.

[9] S. S. Kim, S. M. Lee, and S. C. Hong, "A study on the reaction characteristics of $\mathrm{CO}_{2}$ decomposition using iron oxides," Journal of Industrial and Engineering Chemistry, vol. 18, no. 2, pp. 860-864, 2012.

[10] R. Desai, M. Hussain, and D. M. Ruthven, "Adsorption of water vapour on activated alumina. I-equilibrium behavior," The Canadian Journal of Chemical Engineering, vol. 70, no. 4, pp. 699-706, 1992.

[11] K. Kotoh, M. Enoeda, T. Matsui, and M. Nishikawa, "A multilayer model for adsorption of water on activated alumina in relation to adsorption potential," Journal of Chemical Engineering of Japan, vol. 26, no. 4, pp. 355-360, 1993.

[12] A. Serbezov, "Adsorption equilibrium of water vapor on F-200 activated alumina," Journal of Chemical and Engineering Data, vol. 48, no. 2, pp. 421-425, 2003.

[13] C. R. Reid and K. M. Thomas, "Adsorption of gases on a carbon molecular sieve used for air separation: linear adsorptives as probes for kinetic selectivity," Langmuir, vol. 15, no. 9, pp. 32063218, 1999.

[14] M. M. A. Freitas and J. L. Figueiredo, "Preparation of carbon molecular sieves for gas separations by modification of the pore sizes of activated carbons," Fuel, vol. 80, no. 1, pp. 1-6, 2001.

[15] M. G. Plaza, K. J. Thurecht, C. Pevida et al., "Influence of oxidation upon the $\mathrm{CO}_{2}$ capture performance of a phenolicresin-derived carbon," Fuel Processing Technology, vol. 110, pp. 53-60, 2013.

[16] M. S. Shafeeyan, W. M. A. Wan Daud, A. Houshmand, and A. Arami-Niya, "The application of response surface methodology to optimize the amination of activated carbon for the preparation of carbon dioxide adsorbents," Fuel, vol. 94, pp. 465-472, 2012.

[17] H. Touhara and F. Okino, "Property control of carbon materials by fluorination,” Carbon, vol. 38, no. 2, pp. 241-267, 2000.

[18] Y.-S. Lee, "Syntheses and properties of fluorinated carbon materials," Journal of Fluorine Chemistry, vol. 128, no. 4, pp. 392403, 2007.

[19] A. Tressaud, E. Durand, and C. Labrugère, "Surface modification of several carbon-based materials: comparison between CF4 rf plasma and direct F2-gas fluorination routes," Journal of Fluorine Chemistry, vol. 125, no. 11, pp. 1639-1648, 2004.

[20] Y.-S. Lee and B.-K. Lee, "Surface properties of oxyfluorinated PAN-based carbon fibers," Carbon, vol. 40, no. 13, pp. 24612468, 2002. 
[21] Y. S. Lee, Y. H. Kim, J. S. Hong, J. K. Suh, and G. J. Cho, "The adsorption properties of surface modified activated carbon fibers for hydrogen storages," Catalysis Today, vol. 120, no. 3-4, pp. 420-425, 2007.

[22] F. Chamssedine, K. Guérin, M. Dubois et al., "Fluorination of single walled carbon nanotubes at low temperature: towards the reversible fluorine storage into carbon nanotubes," Journal of Fluorine Chemistry, vol. 132, no. 12, pp. 1072-1078, 2011.

[23] G. Wu, X. Wang, B. Chen et al., "Fluorine-modified mesoporous Mg-Al mixed oxides: Mild and stable base catalysts for $\mathrm{O}$ methylation of phenol with dimethyl carbonate," Applied Catalysis A, vol. 329, pp. 106-111, 2007.

[24] B. M. Choudary, M. Lakshmi Kantam, V. Neeraja, K. Koteswara Rao, F. Figueras, and L. Delmotte, "Layered double hydroxide fluoride: a novel solid base catalyst for C-C bond formation," Green Chemistry, vol. 3, no. 5, pp. 257-260, 2001.

[25] H. Zhou, G. L. Zhuo, and X. Z. Jiang, "Heck reaction catalyzed by Pd supported on LDH-F hydrotalcite," Journal of Molecular Catalysis A, vol. 248, no. 1-2, pp. 26-31, 2006.

[26] Y. S. Lee, Y. H. Kim, J. S. Hong, J. K. Suh, and G. J. Cho, “The adsorption properties of surface modified activated carbon fibers for hydrogen storages," Catalysis Today, vol. 120, no. 3-4, pp. 420-425, 2007.

[27] J. S. Im, S.-J. Park, and Y.-S. Lee, “The metal-carbon-fluorine system for improving hydrogen storage by using metal and fluorine with different levels of electronegativity," International Journal of Hydrogen Energy, vol. 34, no. 3, pp. 1423-1428, 2009.

[28] S. M. Yun, J. W. Kim, M. J. Jung, Y. C. Nho, P. H. Kang, and Y. S. Lee, "An XPS study of oxyfluorinated multiwalled carbon nano tubes," Carbon Letters, vol. 8, no. 4, pp. 292-298, 2007.

[29] M.-J. Jung, J. W. Kim, J. S. Im, S.-J. Park, and Y.-S. Lee, "Nitrogen and hydrogen adsorption of activated carbon fibers modified by fluorination," Journal of Industrial and Engineering Chemistry, vol. 15, no. 3, pp. 410-414, 2009.

[30] J. Jagiello and D. Tolles, Fundamentals of Adsorption, Elsevier, Amsterdam, The Netherlands, 1998, Edited by: F. Meunier.

[31] P. Tarazona, U. Marini Bettolo Marconi, and R. Evans, "Phase equilibria of fluid interfaces and confined fluids," Molecular Physics, vol. 60, no. 3, pp. 573-595, 1987.

[32] Y. Hattori, N. Noguchi, F. Okino et al., "Defluorinationenhanced hydrogen adsorptivity of activated carbon fibers," Carbon, vol. 45, no. 7, pp. 1391-1395, 2007.

[33] P. E. Pehrsson, W. Zhao, J. W. Baldwin et al., "Thermal fluorination and annealing of single-wall carbon nanotubes," Journal of Physical Chemistry B, vol. 107, no. 24, pp. 5690-5695, 2003.

[34] Z. Wu, J. Li, D. Timmer, K. Lozano, and S. Bose, "Study of processing variables on the electrical resistivity of conductive adhesives," International Journal of Adhesion and Adhesives, vol. 29, no. 5, pp. 488-494, 2009.

[35] K. Takai, H. Sato, T. Enoki et al., "Effect of fluorination on nano-sized $\pi$-electron systems," Journal of the Physical Society of Japan, vol. 70, no. 1, pp. 175-185, 2001.

[36] Z. Gu, H. Peng, R. H. Hauge, R. E. Smalley, and J. L. Margrave, "Cutting single-wall carbon nanotubes through fluorination," Nano Letters, vol. 2, no. 9, pp. 1009-1013, 2002.

[37] W. Zhao, C. Song, B. Zheng, J. Liu, and T. Viswanathan, "Thermal recovery behavior of fluorinated single-walled carbon nanotubes," Journal of Physical Chemistry B, vol. 106, no. 2, pp. 293-296, 2002.
[38] T. Nakajima, Fluorine-Carbon and Fluoride-Carbon Materials, Chemistry, Physics, and Applications, CRC Press, New York, NY, USA, 2004.

[39] A. Bismarck, R. Tahhan, J. Springer et al., "Influence of fluorination on the properties of carbon fibres," Journal of Fluorine Chemistry, vol. 84, no. 2, pp. 127-134, 1997.

[40] G. Li, K. Kaneko, S. Ozeki et al., "Water rejective nature of fluorinated microporous carbon fibers," Langmuir, vol. 11, no. 3, pp. 716-717, 1995 

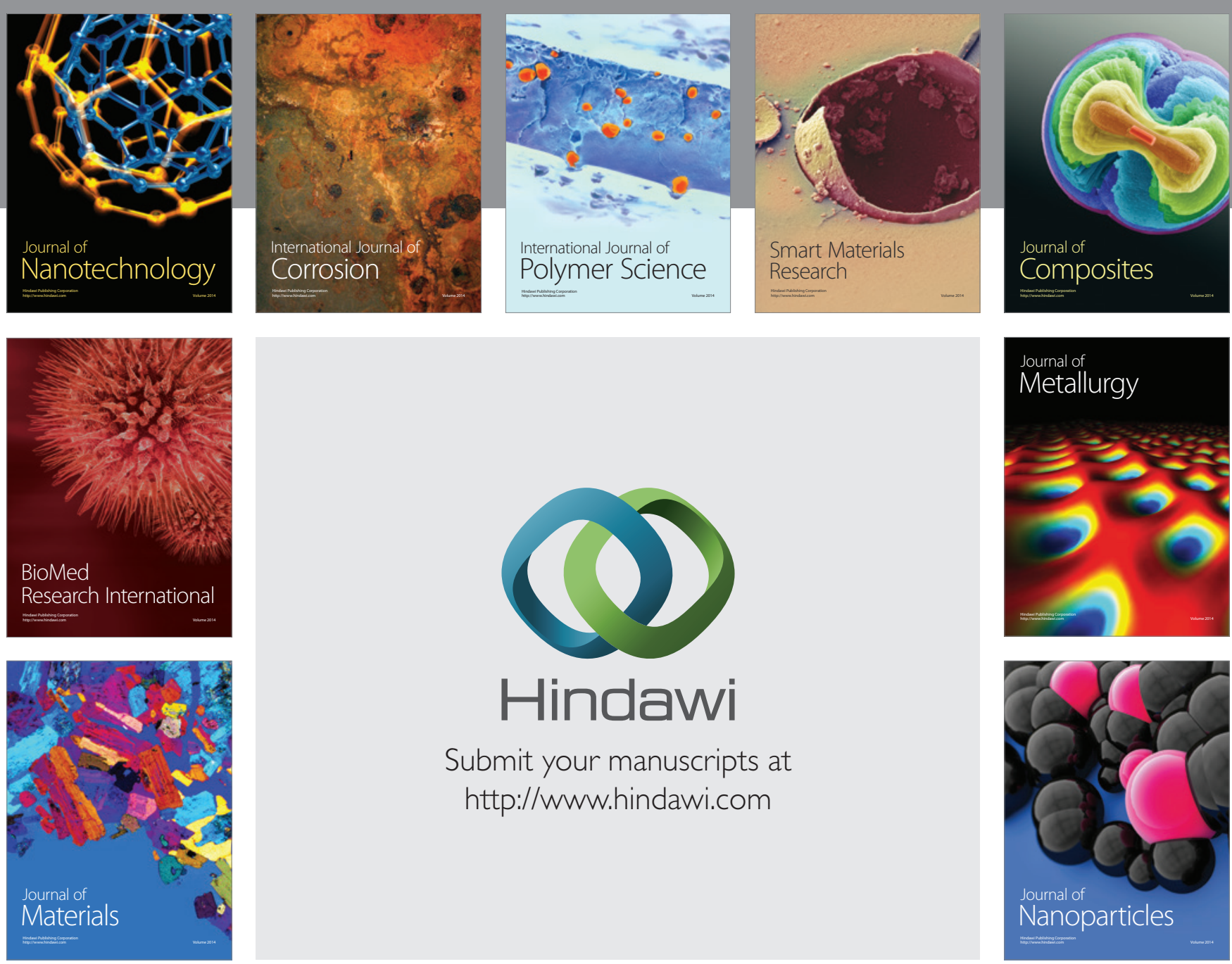

Submit your manuscripts at http://www.hindawi.com
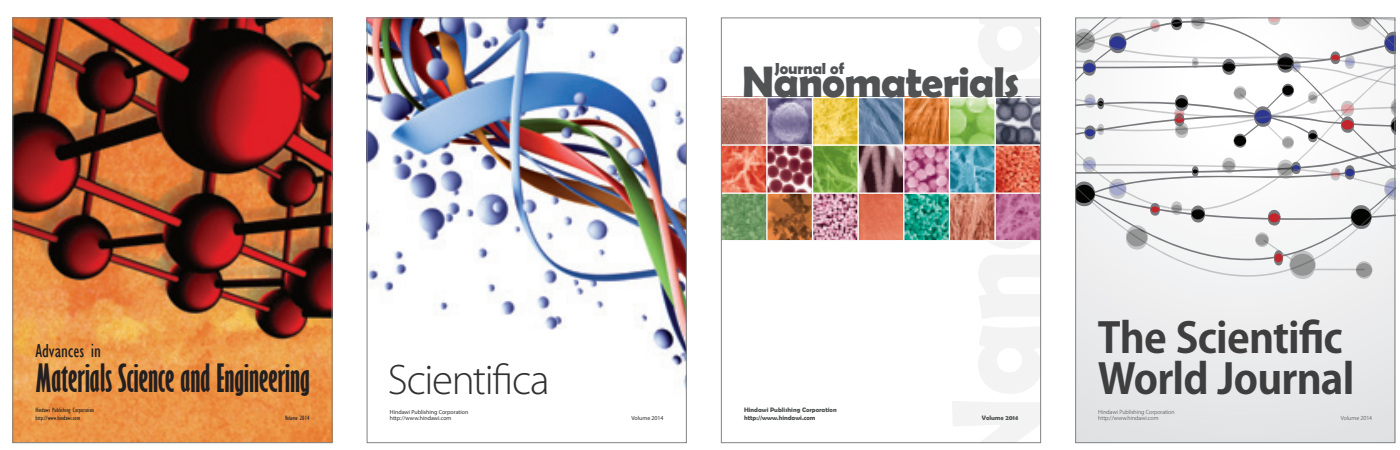

\section{The Scientific World Journal}
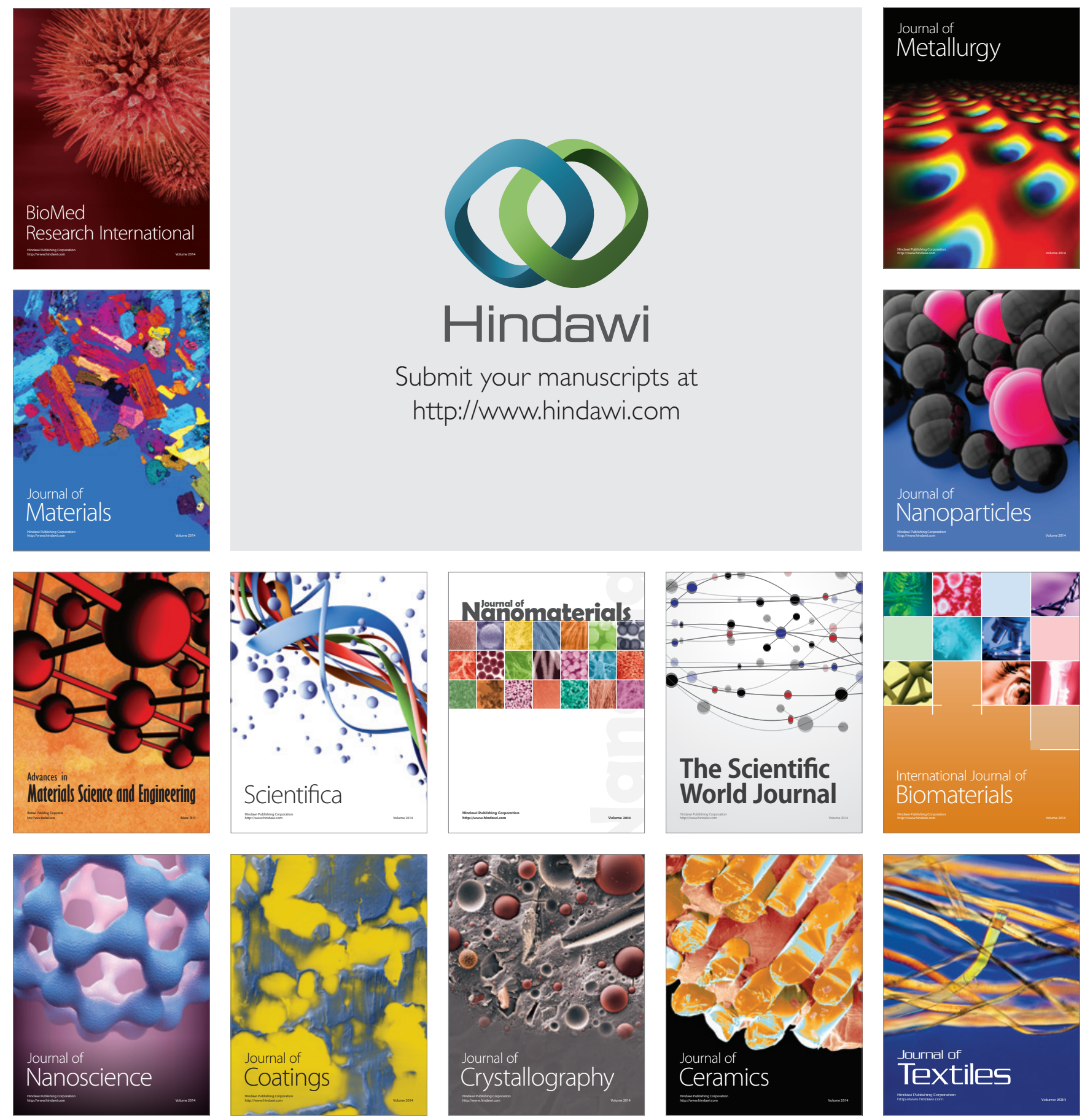